\title{
Triage performance of Swedish physicians using the ATLS algorithm in a simulated mass casualty incident: a prospective cross-sectional survey
}

Maria Lampi*, Tore Vikström and Carl-Oscar Jonson

\begin{abstract}
Background: In a mass casualty situation, medical personnel must rapidly assess and prioritize patients for treatment and transport. Triage is an important tool for medical management in disaster situations. Lack of common international and Swedish triage guidelines could lead to confusion. Attending the Advanced Trauma Life Support (ATLS) provider course is becoming compulsory in the northern part of Europe. The aim of the ATLS guidelines is provision of effective management of single critically injured patients, not mass casualties incidents. However, the use of the ABCDE algorithms from ATLS, has been proposed to be valuable, even in a disaster environment. The objective for this study was to determine whether the mnemonic ABCDE as instructed in the ATLS provider course, affects the ability of Swedish physician's to correctly triage patients in a simulated mass casualty incident.

Methods: The study group included 169 ATLS provider students from 10 courses and course sites in Sweden; 153 students filled in an anonymous test just before the course and just after the course. The tests contained 3 questions based on overall priority. The assignment was to triage 15 hypothetical patients who had been involved in a bus crash. Triage was performed according to the ABCDE algorithm. In the triage, the ATLS students used a colour-coded algorithm with red for priority 1, yellow for priority 2, green for priority 3 and black for dead. The students were instructed to identify and prioritize 3 of the most critically injured patients, who should be the first to leave the scene. The same test was used before and after the course.

Results: The triage section of the test was completed by 142 of the 169 participants both before and after the course. The results indicate that there was no significant difference in triage knowledge among Swedish physicians who attended the ATLS provider course. The results also showed that Swedish physicians have little experience of real mass casualty incidents and exercises.
\end{abstract}

Conclusion: The mnemonic ABCDE doesn't significantly affect the ability of triage among Swedish physicians. Actions to increase Swedish physicians' knowledge of triage, within the ATLS context or separately, are warranted.

Keywords: ATLS, Triage, Disaster, Education, Physicians, Mass casualty incident, Exercises

\section{Introduction}

In a mass casualty situation, medical personnel must rapidly assess and prioritize patients for treatment and transport [1]. Triage is an important tool for medical management in disaster situations [2]. Several national and international triage systems exist to support providers in complex triage decisions.

\footnotetext{
* Correspondence: maria.lampi@lio.se

KMC - Center for Teaching and Research in Disaster Medicine \& Traumatology, University Hospital, Linköping S-58185, Sweden
}

No common international guidelines for mass casualty triage exist. Moreover, few countries have national standards for triage assessment. The absence of guidelines has resulted in great variability in the triage process, tags and nomenclature. The lack of standardized mass casualty triage algorithms could lead to significant confusion. There is limited evidence for the validity of existing triage tools [3-6]. However, an advisory committee in the United States has proposed the SALT (sort, assess, lifesaving interventions, treatment and/or transport) 
Triage System as a US national guideline for mass casualty triage $[7,8]$. A national guideline for mass casualty triage in Norway has recently been developed and published by the Norwegian Directorate of Health. This national standard is based on SALT principles [9].

Advanced Trauma Life Support (ATLS; developed by the American College of Surgeons) is often compulsory and a requirement for a resident degree in anaesthesia, orthopaedics, surgery and emergency medicine in northern Europe [10]. The ATLS program is implemented in more than 60 countries worldwide and more than 1.5 million physicians have participated. The ATLS guidelines are accepted worldwide irrespective of where the injured patient is treated [11,12]. The concept course is designed to teach physicians a standardized approach to trauma care in the first hour after an injury and the course combines the educational formats of lectures and practical lifesaving skills. The ATLS course emphasizes that injury kills in certain time frames. The loss of an airway kills more quickly than loss of the ability to breath. The latter kills more quickly than loss of circulating blood volume. The mnemonic $\mathrm{ABCDE}$ prompt the specific, orders evaluations and interventions that should be followed in all injured patients [13].

ATLS was introduced in Sweden in 1996 and almost 7000 physicians have taken the ATLS provider course since then [14].

It is well established that health care professionals must be adequately prepared for a great variety of casualty events. Exercises and training are essential elements in preparedness [15-18]. Medical teams in a disaster or a mass casualty incident $(\mathrm{MCI})$ are forced to operate in a difficult environment [19]. The objective of the ATLS course is to give the participants skills so that they can identify and treat life-threatening injuries under extreme pressure [13].

The medical teams must have a simple tool that is easy to remember to evaluate and treat the injured patient. The ATLS provider course can be one part in this preparedness as suggested by Dr Walsh after the Granada experience [20]. Physicians involved in the initial treatment in a disaster situation could play a key role if they are highly trained with ATLS $[21,22]$. The ATLS guidelines have been designed to effectively manage single critically injured patients, not patients in MCIs. However, the ATLS course contains several mandatory elements, which are assessed and rated. One element is group discussion, where the aim is to manage multiple patient scenarios and apply trauma triage principles using the mnemonic ABCDE [13].

The subject of disaster medicine is given little time in basic education for Swedish medical students. There is no comprehensive research in Sweden on the topic of knowledge of pre-hospital triage among Swedish physicians attending the ATLS course. Due to the absence of national standards in triage in Sweden, ATLS can be an initiative towards developing national guidelines. One way of measuring triage knowledge is by written tests before and after a course as suggested by previous studies [1,23-25].

The objective for this present work was to determine whether the mnemonic $\mathrm{ABCDE}$ as instructed in the ATLS provider course, affects the ability of Swedish physicians to correctly triage patients in a simulated mass casualty incident.

\section{Methods}

A prospective cross-sectional survey with retrospective analyses of data was designed. The study group contained 169 students of the ATLS provider course from 10 courses and course sites in Sweden during the period between 28 March and 1 June 2012. All students that attended the courses during the timeframe were asked to participate. Demographic data collection included the level of medical education, the number of years in clinical practice, previous experience of simulation exercises and previous experience of real major incidents with more than 5 injured. Triage-tags should be used in the pre-hospital environment, on daily bases in Sweden when more than 5 casualties are involved in the incident $[26,27]$.

The tool chosen for this investigation is a validated instrument that has been tested by Deluhery et al. [1]. For this investigation, permission from the authors was obtained to use and adapt the tool to meet Swedish conditions (Additional file 1). After translation of the questionnaire to Swedish, 5 triage patients were added from the Emergo Train System (ETS) patient database [28]. The 15 patients were 3 red, 3 yellow, 7 green and 2 black according to the $\mathrm{ABCDE}$ and SALT triage algorithms. For additional validation of the instrument, 12 students who participated in a Pre Hospital Life Support (PHTLS) [29] refresher course completed the test before the course with a time limit of 15 minutes. These results are not included in this survey.

The tests were delivered with written instructions to the local ATLS coordinators at the 10 course sites. The coordinators were also briefed by phone. The coordinators distributed the survey to the responders. Together with the pre-course test, the responders were given a written information letter explaining the aim, goals and information about voluntary participation in the survey.

The ATLS students filled in the anonymous tests before and after the course with 3 additional questions based on overall priority. Their assignment was to triage 15 hypothetical patients involved in a bus crash. The students were informed that they were alone at the scene, but more resources were on the way, but were delayed. The student's task was to prioritize the 15 casualties according to the $\mathrm{ABCDE}$ algorithm and take into 
account the postulated circumstances. The student could receive 15 patient points, 1 point for each correctly triaged patient. In the triage, the ATLS students used a colour-coded algorithm with red for priority 1, yellow for priority 2, green for priority 3 and black for dead. The last question in the test was about evacuation from the scene. The student was informed that there were 3 ambulances ready for transport. The respondent's assignment, with no additional patient data, was to identify 3 of the 15 patients that should leave the scene first in these 3 ambulances. The ambulances would leave the incident site at the same time. The same test was used before and after the course.

The tests were completed just before the ATLS provider course and immediately after the course. The time for completing the test in both settings was 15 minutes [23]. The responder coded both tests. After pairing the tests, the coordinators coded the tests and sent them by mail for analyses. The test results were coded, collected and stored in accordance with County Council and University integrity protocols. The regional ethics board was consulted and agreed that the study was not subject to ethical board regulation.

The collected data were recorded in Excel 2011 (Microsoft) for MAC. Statistica (data analysis software system), version 10 (StatSoft) was used for statistical analyses. Descriptive analysis and the paired $t$ test were used to analyze the tests. For analysis between groups, ANOVA and the Tukey post hoc test were used. A $p$-value of less than 0.05 was considered significant.

\section{Results}

The ATLS provider courses were attended by 169 students in Sweden during this survey's timeframe. A total of 153 (90\%) participants voluntarily participated in the survey. 13 students chose not to participate in the survey and no further questions were asked (Table 1). Participant's professional background is illustrated in Figure 1. Overall, 57 (37\%) of the students reported having previous MCI drill experience. Seventeen (11\%) participants had experience of a real major incident involving more than 5 injured people.

Of the 153 participants, 142 (92\%) students completed the triage section in full. The mean pre-course test score for the 142 students was 9.51 patient points. For the post-

Table 1 Number of participants in the different sections of the tests

\begin{tabular}{lllll}
\hline Section & $\begin{array}{l}\text { Available } \\
\text { participants }\end{array}$ & Participants & $\begin{array}{l}\text { Participants with } \\
\text { complete tests }\end{array}$ & $\%$ \\
\hline Triage & 169 & 153 & 142 & 92 \\
Base & 169 & 153 & 153 & 100 \\
Evacuation & 169 & 153 & 146 & 95 \\
\hline
\end{tabular}

course test, the mean score was 9.21 patient points. No statistical significance was found $(p>0.05)$ (Figure 2).

There were no statistical differences in the mean score according to patient points in the pre-course test regarding medical experience, length of education, or those who had previously participated in an exercise situation $(p>0.05)$.

There was no statistical difference between the preand post-course tests regarding the 3 base questions. The mean scores in the pre-course test was 2.57 and 2.65 in the post-course test $(p>0.05)$.

The test included a question on prioritizing the departure of the patients from the scene. This question was independent from the triage section. The result indicated whether the students had identified the most injured patients, the 3 coded red among the 15 casualties. Of the 153 participants, 146 (95\%) completed this section. Eight (5\%) students managed to identify the 3 code red patients before the course and 11 (7\%) students in the post-course test. There were no statistical differences between pre- and post-course test scores $(p>0.05)$.

\section{Discussion}

A test was set out for Swedish ATLS students before and after the course to investigate whether the course influenced the participants' knowledge of triage using the ABCDE algorithm. This study indicates that the ability of triage among the ATLS students did not improve.

Physicians are required to provide urgent care during disasters and become educated in disaster preparedness and management. Previous work has documented that $70-80 \%$ of physicians correctly triaged patients during simulated MCIs [1,30,31]. However, in this study, the participants were able to triage only 9 of the 15 patients (61\%) correctly in both simulated tests. This result is noteworthy and a concern. The results for this study demonstrate no significant differences between the pre- and post-course tests regarding the triage section. This study indicates that the group triage discussion during the ATLS course does not increase the knowledge of triage among Swedish physicians when applying the ABCDE algorithm. Furthermore, the result may have been different if physicians from other Nordic countries had participated due to different educational systems. However, because of the power of the ATLS and its widespread use around the world, it would be advantageous if, after attending an ATLS provider course, participants have basic knowledge of triage.

The physicians in this study are active in different specialties throughout Sweden. Only 11 of 153 participants in this investigation managed to identify the most injured patients and prioritize them for the first available transport. Furthermore, this study found that 17 of 153 physicians have participated in an actual incident with more than 5 


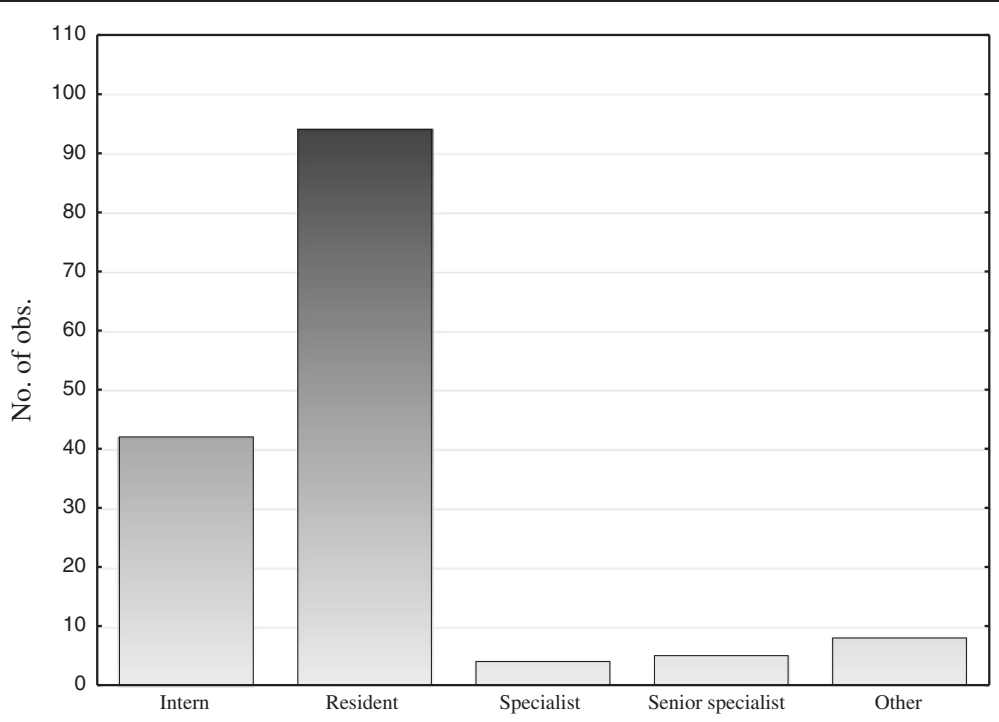

Figure 1 Level of medical education among students.

casualties. Previous studies indicate that if physicians work in a pre-hospital setting during an $\mathrm{MCI}$, it is of great benefit if they do that in their day-to-day work and have proper training $[18,32,33]$. If physicians are to work at MCI sites, specially designed measureable training programs are important [34]. One tool that can contribute to this kind of training may be the Emergo Train System [35]. ETS or similar interactive educational simulation systems could be used to test and evaluate incident command systems, hospital preparedness and triage.

Of the 153 participants in this study, 57 had previously participated in a drill with more than 5 injured people. There is an ongoing discussion in Sweden about the level of education in disaster medicine among medical personnel, especially among medical students, future doctors and nurses. During a national conference in
2012, unpublished data was presented to show that several medical universities in Sweden have not prioritized the topic of disaster medicine at undergraduate level and this development is a concern [36].

Several pre-hospital triage systems exist in Sweden at the present time. This may contribute to difficulties comparing and measuring patient outcomes. Different triage systems may lack a common language if an MCI incident occurs, for example, near county borders. Previous studies have emphasized that one pre-hospital triage system on a national level can be an option $[7,37]$.

The results of this study may initiate a discussion about training and preparedness of Swedish physicians for pre-hospital triage. Further research could include PHTLS students in Sweden taking the same test and comparing the results with this study. This may indicate

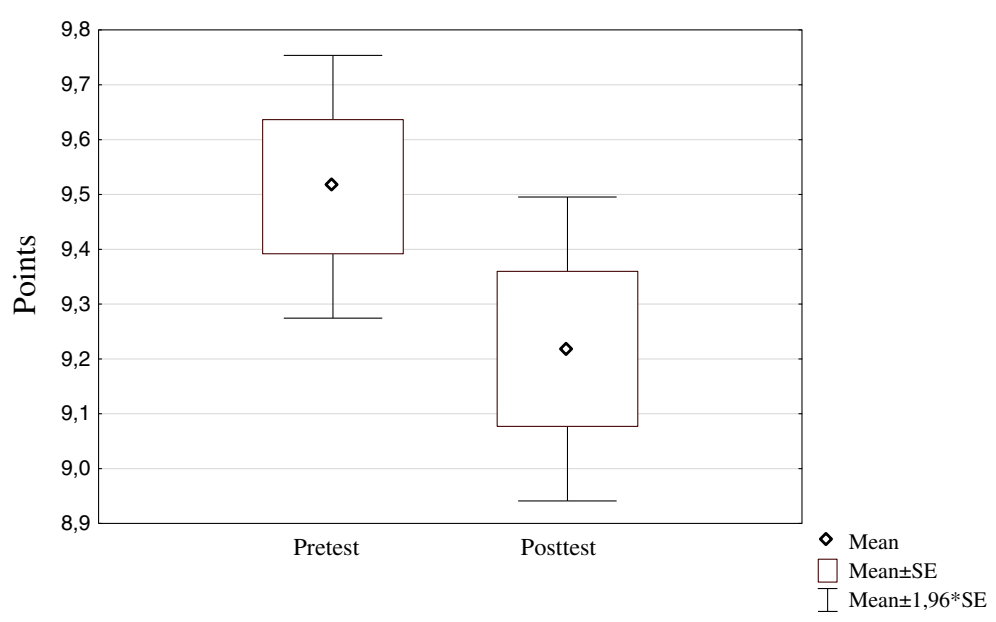

Figure 2 Result of the triage section in the pre- and posttest. 
if PHTLS students are better prepared to perform triage in an $\mathrm{MCI}$, which could reflect that it is easier to learn triage if you work frequently in a pre-hospital setting.

The results of this study are limited to Swedish conditions and to a simulated situation using a questionnaire. The ability to correctly triage patients during a paper exercise scenario may not represent the ability to triage patients in a true MCI.

The participants had access to the ATLS manual 5 weeks before attending the course, which, in theory, could have influenced the pre-course test result. However, ATLS students should be able to score higher in a triage exercise than was evident in this study.

\section{Conclusion}

The physicians who participated in an ATLS provider course in the spring of 2012 in Sweden have been evaluated on their triage knowledge by a pre- and post-course test using a mock drill. The results of this study indicate that the mnemonic ABCDE as instructed in the ATLS provider course doesn't significantly affects the ability of triage among Swedish physicians. The outcome may initiate a discussion about the training and preparedness of Swedish physicians for pre-hospital triage. The outcome of this investigation indicates that experience of real incidents with more than 5 injured people seems to be unusual among Swedish physicians. Furthermore, lack of exercises and training at undergraduate level is a concern. Actions to increase Swedish physicians' knowledge of triage, in the ATLS context or separately, are warranted.

\section{Additional file}

Additional file 1: Pre/Post-Test.

\section{Competing interests}

The authors declare that they have no competing interests.

\section{Authors' contributions}

ML, TV and COJ designed the study. ML performed the data collection and $\mathrm{ML}$ and COJ performed the statistical analysis of the data. ML, COJ and TV contributed to the interpretation. ML and COJ drafted the manuscript. All authors revised the manuscript and approved it in it's the final form.

\section{Acknowledgements}

The authors wish to thank all the ATLS students and the local ATLS coordinators who collected the data. A special thanks to Kristian Åslund at KMC for valuable statistical support.

Received: 2 June 2013 Accepted: 2 December 2013

Published: 20 December 2013

\section{References}

1. Deluhery MR, Lerner EB, Pirrallo RG, Schwartz RB: Paramedic accuracy using SALT triage after a brief initial training. Prehosp Emerg Care 2011, 15(4):526-532.

2. Merin O, Miskin IN, Lin G, Wiser I, Kreiss Y: Triage in mass-casualty events: the Haitian experience. Prehosp Disaster Med 2011, 26(5):386-390.

3. Jenkins JL, McCarthy ML, Sauer LM, Green GB, Stuart S, Thomas TL, Hsu EB: Mass-casualty triage: time for an evidence-based approach. Prehosp Disaster Med 2008, 23(1):3-8.
4. Kilner TM, Brace SJ, Cooke MW, Stallard N, Bleetman A, Perkins GD: In 'big bang' major incidents do triage tools accurately predict clinical priority?: a systematic review of the literature. Injury 2011, 42(5):460-468.

5. Cone DC, Serra J, Burns K, MacMillan DS, Kurland L, Van Gelder C: Pilot test of the SALT mass casualty triage system. Prehosp Emerg Care 2009, 13(4):536-540.

6. Cone DC, Serra J, Kurland L: Comparison of the SALT and Smart triage systems using a virtual reality simulator with paramedic students. Eur J Emerg Med 2011, 18(6):314-321.

7. Lerner EB, Schwartz RB, Coule PL, Weinstein ES, Cone DC, Hunt RC, Sasser SM, Liu JM, Nudell NG, Wedmore IS, Hammond J, Bulger EM, Salomone JP, Sanddal TL, Markenson D, O'Connor RE: Mass casualty triage: an evaluation of the data and development of a proposed national guideline. Disaster Med Public Health Prep 2008, 2(Suppl 1):S25-S34.

8. Lerner EB, Schwartz RB, Coule PL, Pirrallo RG: Use of SALT triage in a simulated mass-casualty incident. Prehosp Emerg Care 2010, 14(1):21-25.

9. Helsedirektoratet: Nasjonal veileder for masseskadetriage. Helsodirektoratet IS-0380 Juni; 2013.

10. Personal communication: ATLS: European Meeting. Berlin; 2012.

11. Maeder MB, Germann S, Banz VM, Amsler F, Driscoll P, Zimmermann H, Exadaktylos AK: Swiss multidisciplinary and multilingual experience of the Advanced Trauma Life Support course: lessons for Europe. Eur J Emerg Med 2012, 19(4):220-225.

12. Thies K, Gwinnutt C, Driscoll P, Carneiro A, Gomes E, Araújo R, Cassar MR, Davis M: The European trauma course-from concept to course. Resuscitation 2007, 74(1):135-141.

13. American Collage of Surgeons: Advanced Trauma Life Support for Doctors ATLS. 9th edition. Chicago, IL; 2012.

14. ATLS: Sverige; 2011. http://www.atls.se

15. Redwood-Campbell L, Abrahams J: Primary health care and disasters-the current state of the literature: what we know, gaps and next steps. Prehosp Disaster Med 2011, 26(3):184-191.

16. Ashkenazi I, Olsha O, Schecter WP, Kessel B, Khashan T, Alfici R: Inadequate mass-casualty knowledge base adversely affects treatment decisions by trauma care providers: survey on hospital response following a terrorist bombing. Prehosp Disaster Med 2009, 24(4):342-347.

17. Yin $\mathrm{H}, \mathrm{He} \mathrm{H}$, Arbon $\mathrm{P}$, Zhu J: A survey of the practice of nurses' skills in Wenchuan earthquake disaster sites: implications for disaster training. J Adv Nurs 2011, 67(10):2231-2238.

18. Aylwin C, König T, Brennan N, Shirley P, Davies G, Walsh M: Reduction in critical mortality in urban mass casualty incidents: analysis of triage, surge, and resource use after the London bombings on July 7, 2005. Lancet 2006, 368:2219-25.

19. Smith E, Wasiak J, Sen A, Archer F, Burkle FM Jr: Three decades of disasters: a review of disaster-specific literature from 1977-2009. Prehosp Disaster Med 2009, 24(4):306-311.

20. Walsh DP, Lammert GR, Devoll J: The effectiveness of the advanced trauma life support system in a mass casualty situation by non-traumaexperienced physicians: Grenada 1983. J Emerg Med 1989, 7(2):175-180.

21. Wolf S, Partenheimer A, Voigt C, Kunze R, Adams HA, Lill H: Primary care hospital for a mass disaster MANV IV. Experience from a mock disaster exercise. Unfallchirurg 2009, 112(6):565-574. in German.

22. Sollid S, Rimstad R, Rehn M, Nakstad A, Tomlinson A, Strand T: Oslo government district bombing and utöya island shooting July 22, 2011: the immediate prehospital emergency medical service response. Scand J Trauma Resusc Emerg Med 2012, 20:3.

23. Gershon RR, Vandelinde N, Magda LA, Pearson JM, Werner A, Prezant D: Evaluation of a pandemic preparedness training intervention of emergency medical services personnel. Prehosp Disaster Med 2009 24(6):>508-511.

24. Sapp RF, Brice JH, Myers JB, Hinchey P: Triage performance of first-year medical students using a multiple-casualty scenario, paper exercise. Prehosp Disaster Med 2010, 25(3):239-245.

25. Kim TE, Reibling ET, Denmark KT: Student perception of high fidelity medical simulation for an international trauma life support course. Prehosp Disaster Med 2012, 27(1):27-30.

26. Radestad M: Erfarenheter och attityder till prioriteringsmarkeringar och skadekort Stockholms Läns Landsting. Stockholms Prehospitala Centrum; 2009.

27. County Council of Östergötland: Kris och katastrofmedicinsk beredskapsplan för Landstinget i Östergötland- utgåva 2010. ; 2010:3601. LiÖ. 
28. Wakasugi M, Nilsson H, Hornwall J, Hornwall J, Vikström T, Rüter A: Can performance indicators be used for pedagogic purposes in disaster medicine training? Scand J Trauma Resusc Emerg Med 2009, 17:15.

29. NAEMT: PHTLS Prehospital Trauma Life Support. 6th edition. Chicago, IL: Elsevier Health Sciences; 2006.

30. Risavi BL, Salen PN, Heller MB, Arcona S: A two-hour intervention using START improves prehospital triage of mass casualty incidents. Prehosp Emerg Care 2001, 5(2):197-199.

31. Kilner T: Triage decisions of prehospital emergency health care providers, using a multiple casualty scenario paper exercise. Emerg Med J 2002, 19(4):348-353.

32. Botker MT, Bakke SA, Christensen EF: A systematic review of controlled studies: do physicians increase survival with prehospital treatment? Scand I Trauma Resusc Emerg Med 2009, 17:12.

33. Hyde P, Mackenzie R, Ng G, Reid C, Pearson G: Availability and utilisation of physician-based pre-hospital critical care support to the NHS ambulance service in England, Wales and Northern Ireland. Emerg Med J 2012, 29(3):177-181.

34. Schuster M, Pints M, Fiege M: Duration of mission time in prehospital emergency medicine: effects of emergency severity and physicians level of education. Emerg Med J 2010, 27(5):>398-403.

35. Nilsson $\mathrm{H}$, Vikstrom T, Jonson CO: Performance indicators for initial regional medical response to major incidents: a possible quality control tool. Scand J Trauma Resusc Emerg Med 2012, 20(1):81.

36. Personal communication: Disasters in the World - Does it Affect Sweden. Stockholm: Karolinska Institut; 2012

37. Welling L, Perez RS, van Harten SM, Patka P, Mackie DP, Kreis RW, Bierens JJ: Analysis of the pre-incident education and subsequent performance of emergency medical responders to the Volendam cafe fire. Eur J Emerg Med 2005, 12(6):265-269.

doi:10.1186/1757-7241-21-90

Cite this article as: Lampi et al:: Triage performance of Swedish physicians using the ATLS algorithm in a simulated mass casualty incident: a prospective cross-sectional survey. Scandinavian Journal of Trauma, Resuscitation and Emergency Medicine 2013 21:90.

\section{Submit your next manuscript to BioMed Central and take full advantage of:}

- Convenient online submission

- Thorough peer review

- No space constraints or color figure charges

- Immediate publication on acceptance

- Inclusion in PubMed, CAS, Scopus and Google Scholar

- Research which is freely available for redistribution 